REVISTA CHILENA DE LITERATURA

Abril 2008, Número 72, 261 - 274

\title{
IV. RESEÑAS
}

Northrop Frye

Anatomy of Criticism: Four Essays.

Toronto: University of Toronto Press, 2006. 450 p.

El más importante estudioso de la literatura canadiense, Northrop Frye (1912-1991) tuvo una vida intelectual extraordinariamente fructífera pero paradójica a la vez ${ }^{1}$. No recibió un grado de Doctor (solo uno de Master, en 1940, de la Universidad de Oxford), pero le fueron otorgados en vida 39 Doctorados Honoris Causae. Su obra, compuesta por 35 libros y más de 500 artículos publicados fue, sin embargo, desafortunadamente reducida, en un momento, a uno solo de sus aspectos constituyentes, el denominado método arquetípico o mitocrítica.

Su sistema teórico, sin embargo, incluía muchos otros aspectos, como una teoría de los géneros discursivos y literarios, una teoría de los símbolos y una teoría de los modos históricos. Y eso, si se piensa solamente en una de las publicaciones de su obra escrita, Anatomía de la crítica: Cuatro ensayos, publicada originalmente en $1957^{2}$. Lo que se reseña aquí es la edición crítica, comentada y editada por Robert Denham, volumen 22, de Collected Works of Northrop Frye, recientemente aparecida, situándola en el ámbito de la producción intelectual de Frye y en relación con el volumen aún inédito dedicado a los Notebooks correspondientes a la Anatomía de la crítica, de próxima aparición.

En efecto, a la obra que fue recibida de manera exitosa pero a la vez crítica, al ser calificada como solo método mítico en su tiempo, ahora se le reconoce también la magnitud teórica y su persistencia en el tiempo. A los 25 volúmenes que publicara en vida, se le agregan ahora 22 volúmenes de sus Obras Completas, póstumamente publicadas y realizadas por Victoria College de la Universidad de Toronto, donde Frye

${ }^{1}$ El presente estudio y reseña de Anatomía de la crítica se ha realizado gracias a un Faculty Research Program 2006-2007, del Department of Foreign Affaires and Internacional Trade, Canadian Studies Program, con un proceso de investigación in situ, en el Frye Center, en la University of Toronto, del 24 de julio al 15 de agosto de 2007, otorgado por la Canadian Embassy en Santiago de Chile.

${ }^{2}$ Caracas: Monte Avila, 1977, 500 p. Incluye Indice de Autores y Títulos citados en el texto. 
impartiera su docencia, gracias a un equipo encabezado por Alvin A. Lee, como editor general y Jean O’Grady, como editora asociada, más un conjunto de destacados editores y consejeros (donde destacan, entre otros, Robert D. Denham, Michael Dolzani y Eva Kushner).

Ahora se percibe con más claridad que hay en su escritura, además de un aporte textual y formal (que es, a la vez, también mítico y antropológico), consistente en una contribución teórica e histórica, amén de cultural y filosófica, en el entramado total de su obra escrita.

En el conjunto de la obra de Frye hay ciertos hitos que implican una formulación de su sistema. Esto acontece en especial inicialmente en su primer libro, Fearful Simmetry: A Study of William Blake, de $1947^{3}$, luego, y principalmente, en su segundo libro, Anatomy of Criticism: Four Essays ${ }^{4}$, una década más tarde, y posteriormente, en 1982, en The Great Code: The Bible and Literatura ${ }^{5}$, el primero de sus libros dedicados al estudio literario de La Biblia y su influencia en la literatura.

Se configura así un proyecto de escritura crítica global, donde cada obra adquiere un sentido modelador de una etapa y oficia de signo reformulador de un sistema que se va enriqueciendo gradualmente.

Frye tuvo conciencia de su proyecto de investigación y escritura como una iniciativa compleja, múltiple y unitaria a la vez, constituida por diferentes facetas. Denominó a este proceso su gran ocho u "ogdoad" ${ }^{6}$. Con ello retomaba el nombre de una deidad del alto Nilo, parte de la cultura egipcia, consistente en ocho diferentes caras o facetas, usualmente ordenadas en cuatro parejas, cuatro masculinas con cuatro femeninas.

El proyecto de escritura de toda una vida de Frye era visto también formado por dos etapas, una lírica, correspondiente al periodo previo a la Anatomía de la crítica ${ }^{7}$ y una épica, el período posterior. Los ocho grandes componentes del ogdoad eran lo liberal (el drama), la tragicomedia (lo épico y lo lírico), el anticlímax (las formas en prosa), el reencuentro, el espejismo, la paradoja, la ignorancia y el ocaso.

${ }^{3}$ Princeton, NJ: Princeton University Press, 1947, 462 p.

${ }^{4}$ Princeton, NJ: Princeton University Press, 1957, X + 383 p.

${ }^{5}$ New York: Harcourt Brace Jovanovich, 1982, XIII + 261 p.

${ }^{6}$ La expresión aparece en la Introducción al volumen 23 de los Collected Works, Northrop Frye's Notebooks for Anatomy of Criticism, libro aún no publicado, pero planeado para el 2008, el cual he tenido la suerte de revisar personalmente en la versión actual (julio 2007) en el Frye Center de la Universidad de Toronto. El volumen será aquí citado como Toronto: University of Toronto Press, 2008, 411 p. Edited by Robert D. Denham (Prefacio, Introducción, Notas).

${ }^{7}$ Nos referimos de aquí en adelante a la edición Anatomy of Criticism. Toronto: University of Toronto Press, 2006, 430 p., ed. Robert Denham. 
La publicación de los 22 volúmenes de las Obras Completas de Frye (con algunas reediciones incluidas) ha posibilitado también el examen del posicionamiento y la transición de su obra, desde el estructuralismo hacia la semiótica, del formalismo hacia lo discursivo, de lo textualista hacia lo post-estructuralista, y de lo moderno a lo post-moderno. Baste con decir que no es clara la situación de Frye con respecto al neocriticismo norteamericano, donde a veces es visto como un participante y otras veces, como un relativizador de dicha corriente.

Una visión del esquema de Frye, tal como se expone en Anatomía de la crítica, por ejemplo, implica percibir una visión global de la historia de la literatura y de sus cambiantes aspectos, marcada por los modos, los géneros, los mitos y los símbolos.

Un aspecto aún por dilucidar por la crítica de Frye son los componentes semióticos de su sistema. No todos están de acuerdo en visualizar en su escritura una aproximación o estrategia semiótica a los fenómenos discursivos y literarios. Una noción central en este sentido podría ser su idea del ciclo y del proceso, como figura omnipresente, donde radica la constante transformación de las formas. Para Frye, el ciclo histórico es un "ritual de imitación de un estado inferior (como todos los rituales imitan a las plantas)"». Ya en Fearful Simmetry ha declarado que la "historia humana, no menos que el mundo natural, posee un ritmo cíclico de declinación y re-nacimiento, y la historia toma la forma de una serie de culturas o civilizaciones, cada una con su propia emergencia, madurez y caída, iniciada mediante una revolución dentro de ella y seguida por una sin ella" ${ }^{9}$.

Otros críticos podrían pensar que el modelo del mensaje literario elaborado por Frye es mirable desde una diversidad de perspectivas, y eso asumiría un carácter semiótico. Todos, sin embargo, están de acuerdo en que Frye tenía una aproximación global constante donde el símbolo asume una posición central.

Otros estudiosos de la obra de Frye podrían argumentar que la lógica de las definiciones de los conceptos literarios realizada por Frye, con su nueva definición según se contemplase desde una nueva perspectiva, cada categoría, sería también de índole semiótica. Finalmente, también habría que considerar aquí su notable trabajo en torno a la intertextualidad, que es para él un mecanismo omnipresente en la historia de la cultura y de la literatura.

Otro aspecto digno de mención es la visión histórica universal de Frye. Esto va más allá de la enorme erudición del teórico canadiense, expresada en la gran cantidad de obras literarias que analiza y a las cuales alude constantemente. Hay en su programa de escritura un modelo histórico que trata la diacronía sincrónicamente, que interfertiliza ambas nociones, encontrando modelos dinámicos y movimientos caracterizadores. El tiempo humano aparece así como una sucesión de modos, símbolos, mitos y géneros.

${ }^{8}$ Nota 124, Frye's Notebooks, 36.

${ }^{9}$ N. Frye. Fearful Simmetry. Ed, Nicholas Lamí and Ian Singer. Toronto: University of Toronto Press, 2004. 210-211. 
Pero, sobre todo, la literatura y su historia son según como la crítica las vea. El rol del analista es fundamental, pues es quien constituye finalmente un corpus de análisis y una historia de la literatura. Dicho de otra manera, Frye necesita realizar una focalización en la crítica para entender la literatura. Se requiere de la interacción entre estos dos lenguajes para que cada uno de ellos sea entendido. En consecuencia, se trata de un sistema intertextual histórico en desarrollo.

El año 2008 se publicará el volumen número 23 de las Obras Completas de Frye, y está dedicado a los Notebooks for Anatomy of Criticism. Frye trabajó doce años en ésta, su obra capital. Algunas notas para el tercer ensayo fueron escritas el 4 de febrero de 1952, en un acto de homenaje al líder canadiense Lester Pearson. Sin embargo, había comenzado Anatomy en los últimos años de la década del 40, inmediatamente luego de publicar en 1947 su estudio sobre la poesía de Blake, que aparentemente le tomó una dedicación de una década (desde que obtuvo una beca para dedicarse a este poeta británico por parte de la Royal Society of Canada en 1936). Este volumen 23 es editado por un gran conocedor de la obra de Frye, Robert Denham, quien está a cargo del prefacio, la introducción y las notas al texto de Frye.

La Anatomía fue creada a partir de catorce ensayos previamente publicados (lo que Frye reconoce en una nota inicial) y de una media docena de artículos que Frye escribió casi simultáneamente. En sus Diarios y Cuadernos de la década del 50 están las huellas de cómo Frye fue dando forma a esta obra fundamental. Declara Frye, según Denham, que dejaba que el libro se escribiera por sí mismo. En efecto, en el "Prefatory Statements and Acknowledgments", en el primer enunciado del libro Anatomía, Frye escribe que "This book forced itself on me while I was trying to write something else" ${ }^{10}$. Al mismo tiempo, Frye dice que odia "las notas amorfas" que parece estar escribiendo ${ }^{11}$.

Una comprensión acerca del carácter postmoderno ya presagiado por Frye lo constituye su afirmación, cuando escribía la Anatomía, de que "la fragmentación representa mejor al hombre de genio de nuestra época"12. Esta idea va en la dirección de la desintegración de los grandes relatos y la aparición de las micrologías postmodernas. Pese a ello, es evidente en la obra el deseo de resumir y unificar, típicamente moderno.

Es importante aquí recordar que Frye tuvo como título para la Anatomía primero el sintagma "El eje y la enciclopedia"13, por una parte, y que por otra, la preocupación de Frye por esos años era desarrollar una teoría de la historia cultural. En la concepción de Frye, no es posible separar la literatura ni de la historia ni de la cultura, como tampoco es posible escindir la cultura de la historia.

${ }^{10}$ N. Frye. Anatomy. Toronto: University of Toronto Press, 2006. 3.

${ }^{11}$ N. Frye. Notebook 7. 115.

${ }^{12}$ N. Frye. Notebooks for Anatomy, citado por Denham en Introduction, por aparecer, XVIII.

${ }^{13}$ N. Frye, Notebooks for Anatomy, citado por Denham en Introduction, por aparecer, XIX. Esto sería aproximadamente en 1950. 
En la primera página de la Anatomía define su tema de estudio como “teoría crítica”, expresión que aún hoy día tiene un sentido progresista ${ }^{14}$. Su interés integrativo es tal, que va más allá de la convergencia entre diacronía y sincronía, intentando aunar lo inductivo más lo deductivo, la ciencia más la filosofía, los casos específicos y las leyes generales.

Frye dice que su "concepción de la Palabra como estructura mental de la sociedad”15 es lo que le interesa desarrollar, y al integrar logos y sociedad, también está haciendo converger "la dialéctica de la literatura y la lógica de la crítica" ${ }^{16}$. Finalmente, también nota que en su gran obra hay "cuatro libros que se colapsaron en uno" 17.

Hoy sabemos que Frye escribió a máquina la Anatomía varias veces (no tenía secretaria en esos años). Persisten 16 cuadernos de notas dedicados a la Anatomía, los cuales serán publicados en su totalidad en el próximo volumen 23 por el Frye Center de la Universidad de Toronto. Anatomía ha sido traducida por lo menos a 15 lenguas, y tal vez en su posición ética y social yazga la importancia que los estudios sobre Frye tienen en China, Italia, Australia, Corea, Canadá y Estados Unidos, países donde se han realizado congresos y homenajes a su obra. Para un estudioso de la literatura tal vez lo más importante sea cómo la realidad toda y la historia humana son vistas por Frye desde el punto de vista de la literatura.

La formación mayormente inglesa (canadiense, británica, estadounidense) de Frye no le dejó tiempo para dedicarse a otras literaturas. Sin embargo, incluyó constantemente en sus referencias a los autores clásicos, de la Antigüedad y de la Edad Media, aunque su campo central de trabajo estuvo siempre constituido por las obras de Shakespeare y la lírica en lengua inglesa de los siglos XVII a XIX. Pocos libros de literatura latinoamericana había en su biblioteca de casi 7000 volúmenes. No había allí ningún libro de Pablo Neruda, pero sí 7 traducciones al inglés de libros de Jorge Luis Borges. Justamente, habría declarado alguna vez que si no se hubiese dedicado a Blake lo habría hecho a un escritor como Borges.

Frye hace uso frecuente de una muy especial ironía. A lo largo de su obra se repiten afirmaciones que tienen, sin embargo, un sentido distinto. La ironía fue la característica que él planteó para su propia época, en su esquema circular y cambiante de las alternativas por las que transcurre la historia literaria.

Un aspecto que tiene que ser más discutido es la relación de Frye con el pensamiento de Aristóteles. Algunos estudiosos de Frye han creído ver en su obra una continuidad con respecto al Estagirita, mientras que otros consideran que más importante

${ }^{14}$ N. Frye. Anatomy. Toronto: University of Toronto Press, 2006. 3.

${ }^{15}$ N. Frye. Notebooks for Anatomy, citado por Denham en Introduction, por aparecer, XXI.

${ }^{16}$ N. Frye. Notebooks for Anatomy, citado por Denham en Introduction, por aparecer, XXI.

${ }^{17}$ Notebook 18. 50. 
que su complementación a algunas ideas de Aristóteles es el hecho de que Frye no se posiciona en una línea analítica sino más bien en una dirección socrática irónica, centrada en el sujeto.

Entre las fuentes o influencias, en la obra de Frye hay numerosas obras que mencionar. Con frecuencia es citada La ciencia nueva de Juan Bautista Vico, con su idea acerca de la preeminencia de lo poético sobre otros tipos de discurso y la idea de las etapas en la historia de la humanidad; la obra poética de Blake, que considera a $L a$ Biblia el gran código cultural y literario para toda producción posterior, y que reelabora una nueva visión mitológica; y la concepción histórica de Spengler, en relación a los ciclos históricos y los momentos de surgimiento, auge y declinación por los cuales pasarían todas las culturas.

El pensamiento de Frye en la Anatomía (o en sus libros sobre la cultura y la literatura canadienses, o en sus escritos sobre educación) reitera muchos de los aspectos que desarrolló en su visión más bien antropológica o de derivaciones religiosas. Ve al ciclo como un rito del tiempo y no del espacio, y hoy podríamos decir que el ciclo es un cronotopo decisivo de la literatura universal. El día es tomado como modelo del año y el año es modelo para el ciclo por el cual transita la literatura.

En el sistema semiótico de Frye, lo natural emerge como modelo para lo social. Lo social reproduce, con innovación, y no mecánicamente, lo natural que le antecede. El día (luz y oscuridad) es una división binaria natural, al igual que su concepción de lo diurno como mañana, tarde y noche. El criterio es siempre lo temporal.

En Frye, el ser humano está marcado por el tiempo, en consonancia con las filosofías del tiempo elaboradas por Martín Heidegger o Jean-Paul Sartre. Lo mismo sucede con las cuatro estaciones del año, que proveen de un modelo tetralógico. Lo numerológico fue siempre un aspecto que le interesó a Frye en sus esquemas (hay numerosos diseños incluidos en sus escritos) y clasificaciones.

La edición que aquí reseñamos es el volumen 22 de las Obras Completas, de 450 páginas. Es imposible consignar todos los aspectos a las que se dirige esta obra de una u otra manera. Recordemos simplemente que no hay en el Archivo base donado por Frye a la Universidad de Toronto un manuscrito de la Anatomía, el cual posiblemente quedó en poder de la editorial de la Universidad de Princeton, en 1957.

Denham rescata las diversas expresiones escritas de Harold Bloom, líder aún de la Escuela de Yale en los estudios literarios, y también incluye la información acerca de que en el periodo de 1964 a 2004, 194 tesis doctorales fueron dedicadas en totalidad o en parte a la obra de Frye. Hasta el 2006, se habían dedicado a la obra de Frye 32 libros, y hasta la fecha (2007) hay unos 1600 artículos dedicados principalmente a su obra escrita, según consignan las bibliografías ${ }^{18}$. Además de Bloom, a quien se considera un seguidor y continuador de Frye (excepto en lo que respecta a la teoría de la

${ }^{18}$ N. Frye. Anatomy. Toronto: University of Toronto Press, 2006, XIX-XX de la Introducción de Denham. 
ansiedad o la escuela del resentimiento), Culler, Jameson, Lentricchia y Ricoeur, entre otros, han escrito positivamente acerca de Frye.

Como ya se ha sugerido, Frye, a través de los modos históricos mediante los cuales se desarrolla la literatura, habría presagiado en Canadá la época postmoderna antes que el libro de Jean Francois Lyotard de 1979, La condición postmoderna, solicitado a este filósofo francés justamente por la Asociación de Universidades Canadienses. Así, el tránsito de lo épico (antigüedad), por lo novelesco y lo lírico (lo moderno), culminaría en lo irónico postmoderno.

Frye ve, en la Anatomía de la crítica, a la historia de la literatura universal (o, por lo menos, occidental) como un texto legible. A ella aplica su espiritu ordenatorio clasificativo y sistematizador de índole dinámica, construyendo y releyendo (o escribiendo por primera vez) el proceso de sus transformaciones. Frye realiza esto mirando simultáneamente al pasado, al presente y al futuro de la literatura.

La anatomía o prospección que realiza del cuerpo literario es muy organizada y de gran complejidad y muchos aún intentan (y han intentado) sistematizar y analizar dicha operación. Esta es ciertamente una lectura obligatoria para todos los estudiosos de la literatura, cualquiera sea la dimensión en que se la aborde. El esquema presentado está focalizado en los procesos de cambio y de influencia intertextual, donde el realismo adquiere una dimensión transformadora como una actividad revolucionaria. Ciertos mitos, o argumentos de historias, vuelven una y otra vez, y adquieren, por lo tanto, un carácter estructurador.

Anatomía es a la vez una obra que estudia a la literatura y que examina a la crítica. Es difícil encontrar otro escrito que aborde de manera tan plena simultáneamente ambos órdenes. La escritura de Frye está llena de ideas centrales que es complejo poder tocarlas todas. Constatemos, simplemente, que para Frye la poesía modela al pensamiento y que la literatura organiza el tiempo.

Luego de una "Introducción polémica”, el primer ensayo de Anatomía de la críti$c a$, se titula "Historical Criticism: Theory of Modes” (pp. 31-63) ${ }^{19}$ y está centrado en la figura del héroe, y en la literatura universal se han desarrollado cinco modos, unos tras otros: el mito (Antigüedad clásica), el romance (Edad Media), el mimético alto (Renacimiento), el mimético bajo (siglo xIx) y el irónico (siglo xx). Cada modo puede ser a su vez, trágico o cómico, enciclopédico o episódico.

El segundo ensayo de Anatomía es "Ethical Criticism: Theory of Symbols” (pp. 65-119). El aspecto central ahora es el simbolismo y sus distintas fases, niveles o metodologías, cinco en total: literal (los motivos), descriptiva (los signos), formal (las imágenes), mítica (los archetipos) y anagógica (las mónadas). Cada fase se vincula a un cierto tipo de arte y un determinado tipo de crítica.

\footnotetext{
${ }^{19}$ Los números de páginas de los cuatro ensayos se refieren a la edición de las Obras Completas, N. Frye. Anatomy. Toronto: University of Toronto Press, 2006, 450 p.
} 
El tercer ensayo es “Archetypal Criticism: Theory of Myths”, (pp. 121-223), donde lo central es el significado de las narraciones. Hay aquí primero una teoría del significado arquetípico, con sus tres tipos de imaginería, apocalíptica, demoníaca y analógica, para luego tratar los modelos narrativos básicos, que son cuatro, correspondiendo a las estaciones del año: la comedia (primavera), el romance (verano), la tragedia (otoño) y finalmente la ironía y la sátira (el invierno).

El cuarto y último ensayo de la Anatomía es "Rethorical Criticism: Theory of Genres” (pp. 225-316) donde lo fundamental son los cuatro géneros principales, los que están a su vez caracterizados por un tipo de ritmo propio, respectivamente, con lo cual tenemos la recurrencia de lo épico, la continuidad de la prosa, el decoro del drama y la asociación de la lírica. El volumen se cierra con una "Conclusión tentativa”.

Según el crítico canadiense, todos los temas y formas ya han sido tratados, pero vuelven de manera diferente, una y otra vez. Las obras concretas están ligadas a los grandes sistemas dicursivos, genéricos, históricos, argumentales. Frye demuestra una gran habilidad para ver un mismo fenómeno literario desde distintas aproximaciones diferenciadas. Un elemento significa una cosa en una estructura discursiva, y al estar posicionado en otra, adquiere una nueva significación.

Frye analiza una gran cantidad de obras, autores, géneros, medios, modos, en la Anatomía, centrado siempre en el proceso de comunicación, el cual enriquece, al ser entendido el lenguaje como cohesionador de la experiencia humana. Su propio punto de vista es incluido y teorizado al final de la Anatomía, donde hace sinónimos la sátira menipea y la anatomía, como mecanismos analíticos e ironizadores.

Frye no se preocupó solamente de los simbolismos y los modelos. Su uso de la noción de mito es enriquecedor; nunca dejó de lado el contexto discursivo de los procesos de significación y trazó claramente el desarrollo de lo mitológico hasta lo realista. Su habilidad la aplicó a la sociedad y a la cultura, y a su propia peripecia personal en Canadá, y no fue restringida solo a los textos. Abarcó tanto la dimensión profana como la dimensión numinosa y produjo en su múltiple escritura tanto un sentido de historia nacional como de identidad patria para los canadienses.

Northrop Frye fue un gran profesor, de quien escuchamos clases memorables e inolvidables. También fue un escritor extraordinario, cuya obra desconocemos (aún faltan algunos volúmenes por publicar de sus Obras Completas). Su palabra humana, aferrada al tiempo y al espacio, es de una riqueza insospechada para muchos. Otros, unos pocos, han tenido la suerte de comprenderlo en el marco efímero de sus vidas.

MANUEl JofRÉ

Universidad de Chile

mjofre@uchile.cl 